\title{
Respiratory Syncytial Virus Pneumonia Treated with Lower-Dose Palivizumab in a Heart Transplant Recipient
}

\author{
J. L. Grodin, ${ }^{1}$ K. S. Wu, ${ }^{1}$ E. E. Kitchell, ${ }^{1,2}$ J. Le, ${ }^{1,2}$ J. D. Mishkin, ${ }^{1,3}$ \\ M. H. Drazner, ${ }^{1,3}$ and D. W. Markham ${ }^{1,3}$ \\ ${ }^{1}$ Department of Internal Medicine, UT Southwestern Medical Center, Dallas, TX 75390, USA \\ ${ }^{2}$ Division of Infectious Diseases, Department of Internal Medicine, UT Southwestern Medical Center, Dallas, TX 75390, USA \\ ${ }^{3}$ Division of Cardiology, Department of Internal Medicine, UT Southwestern Medical Center, Dallas, TX 75390, USA
}

Correspondence should be addressed to D. W. Markham, david.markham@utsouthwestern.edu

Received 3 October 2011; Accepted 20 October 2011

Academic Editors: K.-R. Chiou and T. Kasai

Copyright () 2012 J. L. Grodin et al. This is an open access article distributed under the Creative Commons Attribution License, which permits unrestricted use, distribution, and reproduction in any medium, provided the original work is properly cited.

\begin{abstract}
Respiratory syncytial virus (RSV) is an important community-acquired pathogen that can cause significant morbidity and mortality in patients who have compromised pulmonary function, are elderly, or are immunosuppressed. This paper describes a 70-year-old man with a remote history of heart transplantation who presented with signs and symptoms of pneumonia. Chest computed tomography (CT) imaging demonstrated new patchy ground glass infiltrates throughout the upper and lower lobes of the left lung, and the RSV direct fluorescence antibody (DFA) was positive. The patient received aerosolized ribavirin, one dose of intravenous immunoglobulin, and one dose of palivizumab. After two months of followup, the patient had improved infiltrates on chest CT, improved pulmonary function testing, and no evidence of graft rejection or dysfunction. There are few data on RSV infections in heart transplant patients, but this case highlights the importance of considering this potentially serious infection and introduces a novel method of treatment.
\end{abstract}

\section{Introduction}

Respiratory syncytial virus (RSV) is an enveloped RNA virus belonging to the family of Paramyxoviridae and is primarily known as a common infection in children [1]. However, this community-acquired respiratory viral infection can cause significant morbidity and mortality in patients who have compromised pulmonary function, are elderly, or are immunosuppressed $[2,3]$.

Other respiratory viruses have been reported in adult heart transplant recipients [4-6]. There are little data regarding the natural history, treatment, and prognosis of RSV pneumonia in adult heart transplant recipients. We reviewed two previous case reports in the literature $[7,8]$. The first report described a patient who became ill 60 days post-transplantation and was treated successfully with aerosolized ribavirin. The second describes a patient with a fever of unknown origin who was diagnosed with RSV pneumonia by gallium scan three years posttransplantation. In this paper there is no discussion of treatment or outcome. Our patient is unique as he was 10 years posttransplant and had been weaned off prednisone.

\section{Case Report}

A 70-year-old Caucasian man with a history of orthotopic heart transplantation (OHT) in 1999 for an ischemic cardiomyopathy presented with a five-day history of rhinorrhea, mylagias, and subjective fevers. In addition, he noted worsening orthopnea and an inability to lay flat without using a continuous positive airway pressure device. Subsequently he developed dyspnea with a productive cough of gray/white sputum. A routine posttransplant computed tomogram (CT) scan of the chest six months prior to admission revealed extensive atelectasis in the basal segments of the left lower lobe and lingula. A repeat CT scan two months prior to admission revealed worsening atelectasis of the left lower lobe (Figure 1). He therefore underwent a transbronchial biopsy of his left lower lobe. The pathology was unremarkable. Bronchial fluid cultures grew normal respiratory 


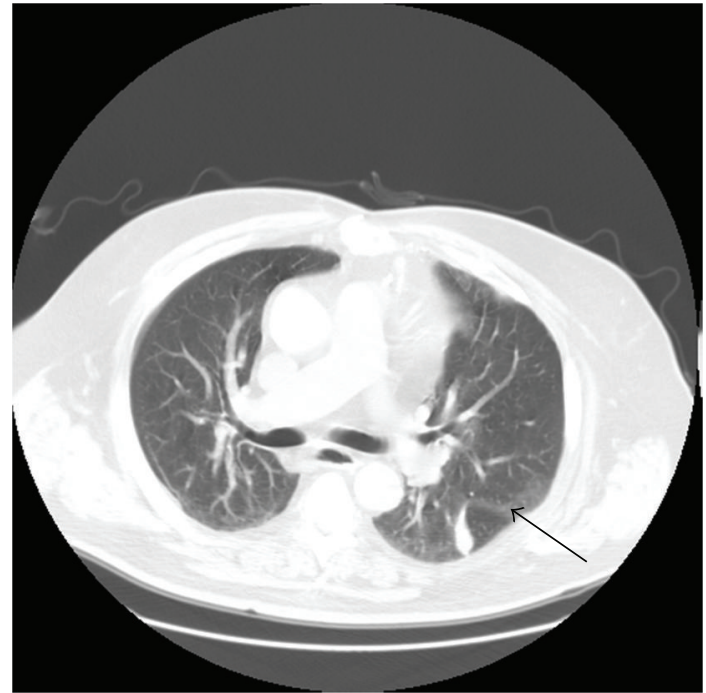

FIGURE 1: Chest computed tomogram with intravenous contrast two months prior to admission revealing atelectasis of the left lower lobe (arrow).

TABLe 1: Pulmonary function tests two months prior to admission and at three months followup.

\begin{tabular}{lcc}
\hline PFT & Prior to admission & Followup \\
\hline FVC (liters), (\% predicted) & $2.01,(45 \%)$ & $2.76,(68 \%)$ \\
FEV1 (liters), (\% predicted) & $1.58,(53 \%)$ & $2.21,(74 \%)$ \\
FEV1/FVC (\% predicted) & 78 & 80 \\
\hline
\end{tabular}

FVC: forced vital capacity, FEV1: forced expiratory volume in one second.

flora and cytology was negative for malignancy. Pulmonary function tests (PFTs) at that time were consistent with a restrictive physiology (Table 1). On the day of admission, the patient presented with symptoms suggestive of an acute infectious upper and lower respiratory process and worsening orthopnea from baseline. The chest radiograph (not shown) and CT of his chest at this time revealed new patchy ground glass infiltrates throughout the upper and lower lobes of the left lung (Figure 2).

Past medical history includes Type II diabetes mellitus with nephropathy, retinopathy, and neuropathy; obesity (BMI of $39.5 \mathrm{~kg} / \mathrm{m}^{2}$ ); nonalcoholic fatty liver disease; chronic peripheral edema and venous stasis; resected melanoma; basal cell carcinoma of the face; hypertension; dyslipidemia. He was a former heavy smoker prior to his heart transplantation, rarely consumed alcoholic beverages, denied any previous illicit or intravenous drug abuse, and was unable to recall any recent sick contacts. Medications on admission were cyclosporine ( $100 \mathrm{mg}$ orally twice daily), mycophenolate mofetil $(250 \mathrm{mg}$ orally twice daily), insulin glargine, furosemide, simvastatin, enalapril, trimethoprim-sulfamethoxazole, diltiazem, acetaminophen, aspirin, fenofibrate, vitamin $\mathrm{E}$, and vitamin $\mathrm{C}$.

Physical examination revealed an obese man in mild respiratory distress. He was afebrile with a temperature of 36.7 degrees Celsius. The pulse was 118 and regular,

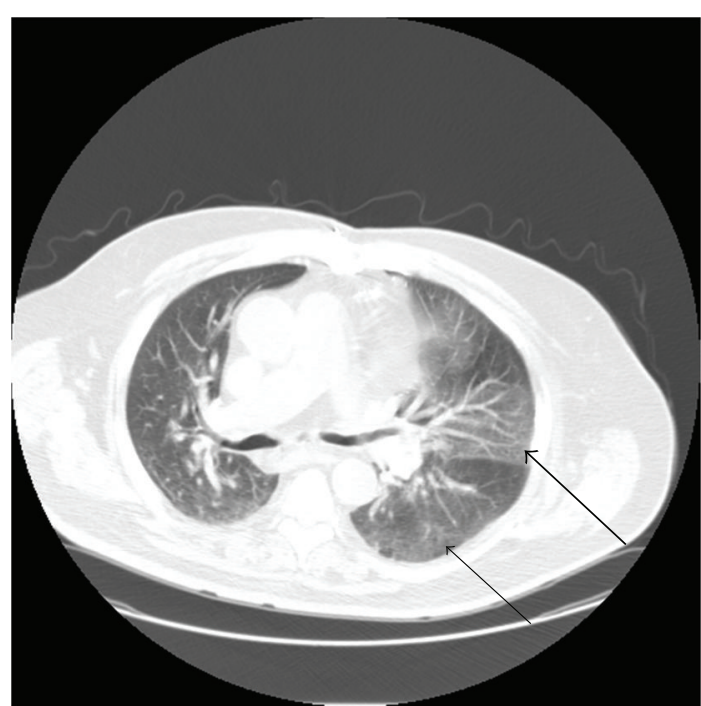

Figure 2: Admission chest computed tomogram with intravenous contrast revealing new ground glass infiltrates of the upper (bold arrow) and lower (narrow arrow) lobes of the left lung.

blood pressure $148 / 74$, oxygen saturation $88 \%$ on room air improving to $94 \%$ on 3 liters of oxygen, and weight $118 \mathrm{~kg}$. He was breathing approximately 24 times per minute and had bilateral rales at the bases of his lungs. Other than tachycardia, his cardiovascular exam was unremarkable. The remainder of his examination was remarkable for $3+$ pitting edema of the lower extremities with venous stasis changes up to the superior portion of his calves.

Upon arrival to the intensive care unit, an arterial blood gas revealed a $\mathrm{pH}$ of $7.29, \mathrm{PCO}_{2}$ of $74 \mathrm{mmHg}$, and $\mathrm{PO}_{2}$ of $48 \mathrm{mmHg}$. The results of multiple serologies and cultures were negative except for a positive RSV direct fluorescence antibody (DFA).

Given the severity of his symptoms, he was treated with 5 days of aerosolized ribavirin (Virazole $2 \mathrm{gm}$ inhaled every 8 hours), one dose of IV immunoglobulin (Gamunex $400 \mathrm{mg} / \mathrm{kg}=50,000 \mathrm{mg}$ ), and, due to financial constraints, a single half-dose of palivizumab (Synagis $7.5 \mathrm{mg} / \mathrm{kg}=$ $900 \mathrm{mg}$ ) [9]. In addition, he received temporary bilevel positive airway pressure ventilation (BiPAP) and 3 days of intravenous methylprednisolone ( $40 \mathrm{mg}$ daily). After five days of treatment, a repeat RSV DFA was negative. He was subsequently weaned off of BiPAP and released from the hospital. Three months later, a follow-up CT scan of his chest revealed resolution of his ground glass infiltrates (Figure 3) and improvement of his PFTs from baseline (Table 1). He had no evidence of allograft rejection or dysfunction.

\section{Discussion}

In the United States, most RSV infections occur throughout a period of approximately 22 weeks from the late fall to late spring [1]. Peak activity occurs during the months of January and February. Syndromes of RSV infection in adults include 


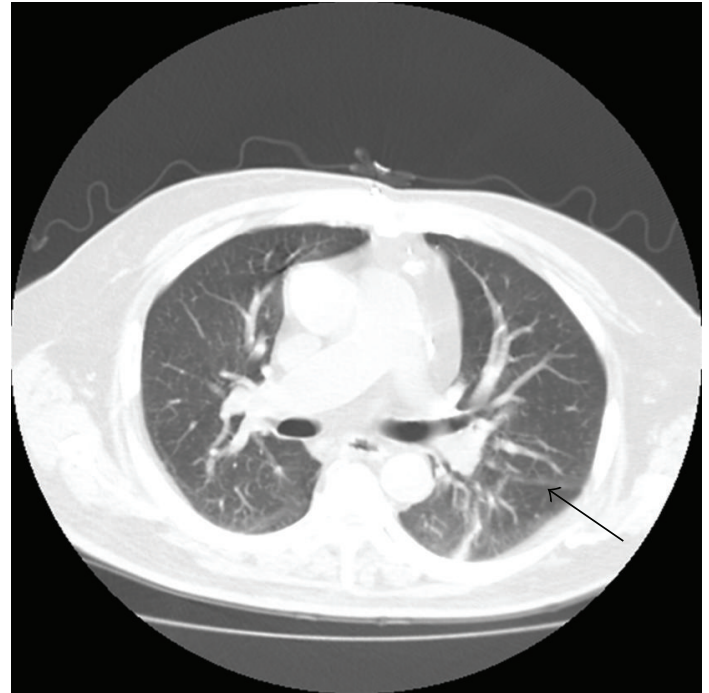

Figure 3: Chest computed tomogram with intravenous contrast three months after admission with resolved ground glass infiltrates revealing the initial atelectasis of the left lower lobe present two months prior to admission (arrow).

mild upper respiratory illnesses, bronchitis/bronchiolitis, pneumonia, and fulminant respiratory failure [3].

We find this paper clinically essential as there is both a paucity of information regarding the treatment for RSV pneumonia in OHT recipients and a lower dose of palivizumab may be sufficient. We treated our patient based on the experience reported in the bone marrow and lung transplant literature [6-8]. Aerosolized ribavirin decreases viral load in adults following bone marrow transplantation but may have little efficacy on mortality [10]. In patients with lung transplantation, aerosolized ribavirin increases the likelihood of improvement in forced expiratory volume in one second, lowers rates of bronchiolitis obliterans, and may yield a complete recovery [10-12]. Evidence suggests that the addition of palivizumab (a humanized anti-RSV antibody) or intravenous immunoglobulin (IVIG) may improve survival in patients after bone marrow transplantation and decrease the incidence of bronchiolitis obliterans and rejection in patients after lung transplantation [13-16]. However, at the recommended dose (Table 2) [9], palivizumab treatment in an adult may cost more than $\$ 10,000$ [17]. Newer experimental therapies have been reviewed elsewhere [18]. To date there is no consensus on treatment of RSV pneumonia, but it has been suggested that use of aerosolized ribavirin and antibody therapy should be considered in patients with upper respiratory tract symptoms and other risk factors (i.e., posttransplant immunosuppression) [19].

\section{Conclusion}

In summary, little is known about RSV infections in orthotopic heart transplant recipients. Given the serious consequences of RSV pneumonia following bone marrow or lung transplantation, RSV pneumonia should be included in
TABLE 2: Common treatments for RSV respiratory tract infection.

\begin{tabular}{|c|c|c|}
\hline Drug & Dosage & Frequency \\
\hline \multicolumn{3}{|l|}{ Ribavirin } \\
\hline Aerosolized & $2 g$ & $\begin{array}{l}\text { Every } 8 \text { hours for } 15 \text { total } \\
\text { doses }\end{array}$ \\
\hline Oral / IV* & $15-20 \mathrm{mg} / \mathrm{kg}$ & $\begin{array}{l}\text { Divided in } 3 \text { doses over } 10 \\
\text { days }\end{array}$ \\
\hline \multicolumn{3}{|c|}{ Corticosteroids $^{\dagger}$} \\
\hline Solu-Medrol & $10-15 \mathrm{mg} / \mathrm{kg} /$ day & Over 3 days \\
\hline IVIG & $0.5 \mathrm{~g} / \mathrm{kg}$ & Once \\
\hline Palivizumab & $15 \mathrm{mg} / \mathrm{kg}$ & Once \\
\hline Motavizumab $^{\ddagger}$ & $3-15 \mathrm{mg} / \mathrm{kg}$ & Once \\
\hline
\end{tabular}

RSV: respiratory syncytial virus, IVIG: intravenous immunoglobulin.

* IV ribavirin with oral corticosteroids is well tolerated and effective with a lower price than aerosolized ribavirin [20].

${ }^{\dagger}$ There is no consensus as to the appropriate regimen. Steroid selection and dosing are usually center dependent.

${ }^{\ddagger}$ Motavizumab is a new, potent anti-RSV immunoglobulin, recently not approved by the FDA in a recent filing for licensure [21].

the differential diagnosis in patients after OHT who present with a viral prodrome and abnormal lung imaging. Although there are no data regarding treatment and outcomes of RSV infection in heart transplant recipients, our patient appeared to have good clinical response to an approach from the bone marrow and lung transplant literature with a lower palivizumab dose. Further study regarding the frequency and optimal therapeutic approach for RSV infections in heart transplant recipients is needed.

\section{Conflict of Interests}

The authors of this paper have no conflict of interests to disclose.

\section{Authors' Contribution}

All authors contributed in drafting, critical revision, and approval of this paper.

\section{References}

[1] C. B. Hall, "Respiratory syncytial virus and parainfluenza virus," The New England Journal of Medicine, vol. 344, no. 25, pp. 1917-1928, 2001.

[2] M. M. Chakinala and M. J. Walter, "Community acquired respiratory viral infections after lung transplantation: clinical features and long-term consequences," Seminars in Thoracic and Cardiovascular Surgery, vol. 16, no. 4, pp. 342-349, 2004.

[3] A. R. Falsey, P. A. Hennessey, M. A. Formica, C. Cox, and E. E. Walsh, "Respiratory syncytial virus infection in elderly and high-risk adults," The New England Journal of Medicine, vol. 352, no. 17, pp. 1749-1759, 2005.

[4] F. López-Medrano, J. M. Aguado, M. Lizasoain et al., "Clinical implications of respiratory virus infections in solid organ transplant recipients: a prospective study," Transplantation, vol. 84, no. 7, pp. 851-856, 2007. 
[5] A. Humar, D. Kumar, T. Mazzulli et al., "A surveillance study of adenovirus infection in adult solid organ transplant recipients," American Journal of Transplantation, vol. 5, no. 10, pp. 2555-2559, 2005.

[6] R. P. Embrey and L. J. Geist, "Influenza A pneumonitis following treatment of acute cardiac allograft rejection with murine monoclonal anti-CD3 antibody (OKT3)," Chest, vol. 108, no. 5, pp. 1456-1459, 1995.

[7] J. T. Sinnott, J. P. Cullison, M. S. Sweeney, M. Hammond, and D. A. Holt, "Respiratory syncytial virus pneumonia in a cardiac transplant recipient," Journal of Infectious Diseases, vol. 158, no. 3, pp. 650-651, 1988.

[8] N. Berbari, D. H. Johnson, and B. A. Cunha, "Respiratory syncytial virus pneumonia in a heart transplant recipient presenting as fever of unknown origin diagnosed by gallium scan," Heart and Lung, vol. 24, no. 3, pp. 257-259, 1995.

[9] K. L. Hicks, R. F. Chemaly, and D. P. Kontoyiannis, "Common community respiratory viruses in patients with cancer: more than just "common colds"," Cancer, vol. 97, no. 10, pp. 2576$2587,2003$.

[10] C. H. Wendt, J. M. K. Fox, and M. I. Hertz, "Paramyxovirus infection in lung transplant recipients," Journal of Heart and Lung Transplantation, vol. 14, no. 3, pp. 479-485, 1995.

[11] L. H. McCurdy, A. Milstone, and S. Dummer, "Clinical features and outcomes of paramyxoviral infection in lung transplant recipients treated with ribavirin," Journal of Heart and Lung Transplantation, vol. 22, no. 7, pp. 745-753, 2003.

[12] I. Uçkay, P. M. Gasche-Soccal, L. Kaiser et al., "Low incidence of severe respiratory syncytial virus infections in lung transplant recipients despite the absence of specific therapy," Journal of Heart and Lung Transplantation, vol. 29, no. 3, pp. 299305, 2010.

[13] S. Ghosh, R. E. Champlin, S. A. Giralt et al., "Respiratory syncytial virus upper respiratory tract illnesses in adult blood and marrow transplant recipients: combination therapy with aerosolized ribavirin and intravenous immunoglobulin," Bone Marrow Transplantation, vol. 25, no. 7, pp. 751-755, 2000.

[14] D. A. Tsitsikas, H. Oakervee, J. D. Cavenagh, J. Gribben, S. G. Agrawal, and F. M. Mattes, "Treatment of respiratory syncytial virus infection in haemopoietic stem cell transplant recipients with aerosolized ribavirin and the humanized monoclonal antibody palivizumab: a single centre experience," British Journal of Haematology, vol. 146, no. 5, pp. 574-576, 2009.

[15] E. Whimbey, R. E. Champlin, J. A. England et al., "Combination therapy with aerosolized ribavirin and intravenous immunoglobulin for respiratory syncytial virus disease in adult bone marrow transplant recipients," Bone Marrow Transplantation, vol. 16, no. 3, pp. 393-399, 1995.

[16] R. E. Champlin and E. Whimbey, "Community respiratory virus infections in bone marrow transplant recipients: the M.D. Anderson Cancer Center experience," Biology of Blood and Marrow Transplantation, vol. 7, no. 12, supplement, pp. 8S-10S, 2001.

[17] F. S. de Fontbrune, M. Robin, R. Porcher et al., "Palivizumab treatment of respiratory syncytial virus infection after allogeneic hematopoietic stem cell transplantation," Clinical Infectious Diseases, vol. 45, no. 8, pp. 1019-1024, 2007.

[18] J. N. Shah and R. F. Chemaly, "Management of RSV infections in adult recipients of hematopoietic stem cell transplantation," Blood, vol. 117, no. 10, pp. 2755-2763, 2011.

[19] M. G. Ison and M. G. Michaels, "RNA respiratory viral infections in solid organ transplant recipients," American Journal of Transplantation, vol. 9, supplement 4, pp. S166-S172, 2009.
[20] A. R. Glanville, A. I. R. Scott, J. M. Morton et al., "Intravenous ribavirin is a safe and cost-effective treatment for respiratory syncytial virus infection after lung transplantation," Journal of Heart and Lung Transplantation, vol. 24, no. 12, pp. 21142119, 2005.

[21] M. A. Gill and R. C. Welliver, "Motavizumab for the prevention of respiratory syncytial virus infection in infants," Expert Opinion on Biological Therapy, vol. 9, no. 10, pp. 1335-1345, 2009. 


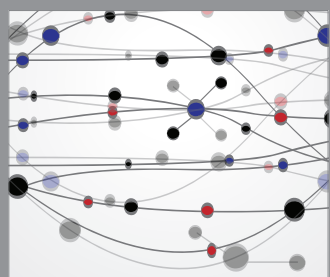

The Scientific World Journal
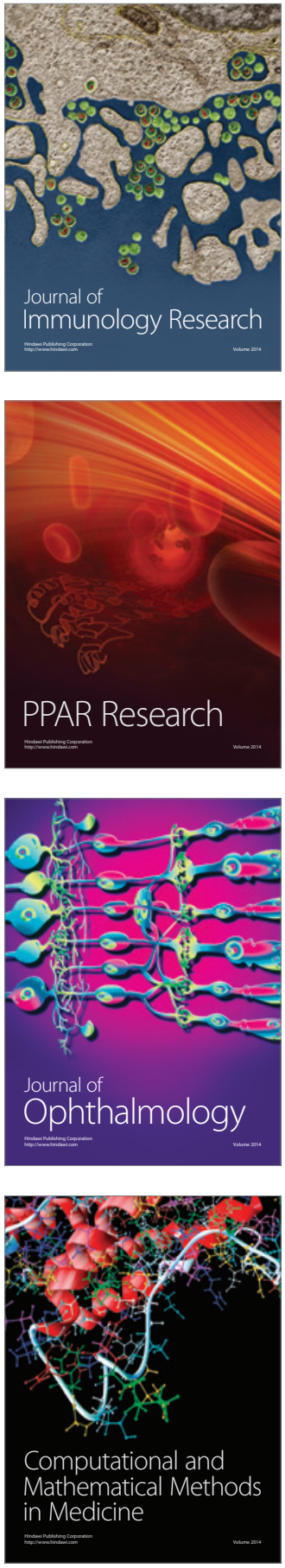

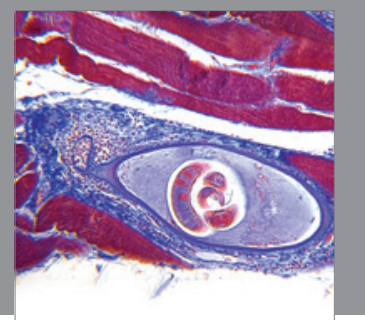

Gastroenterology

Research and Practice
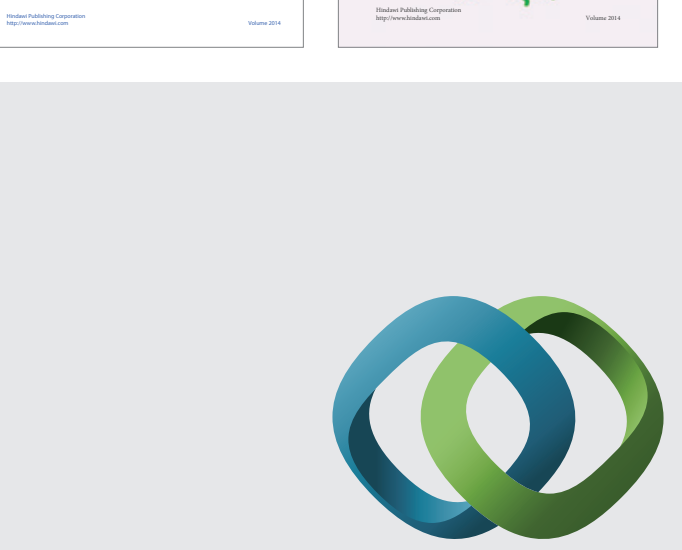

\section{Hindawi}

Submit your manuscripts at

http://www.hindawi.com
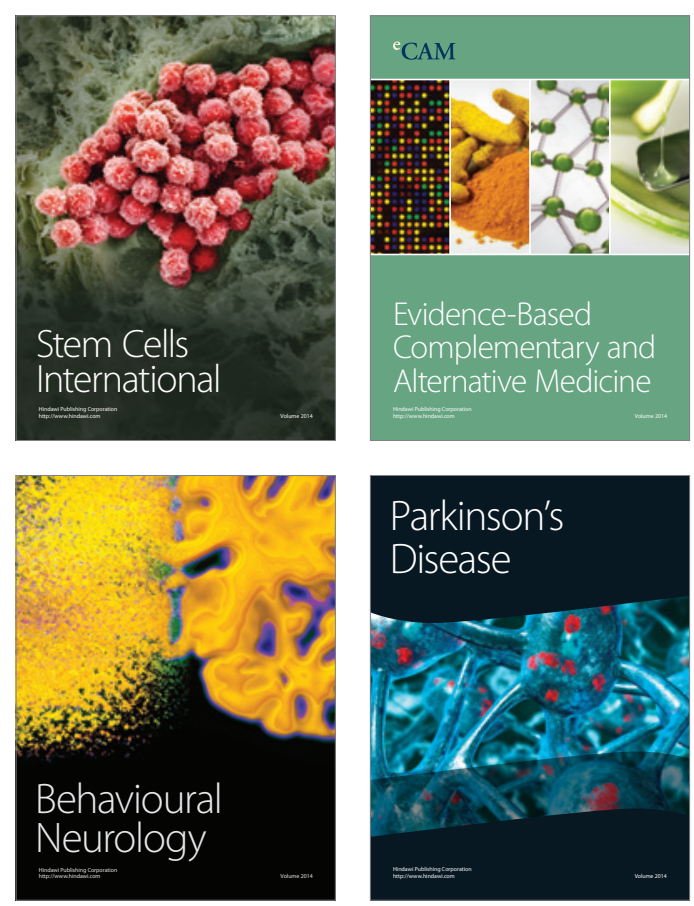

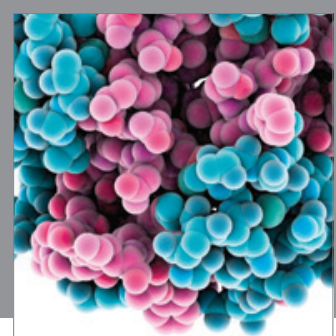

Journal of
Diabetes Research

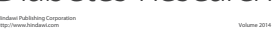

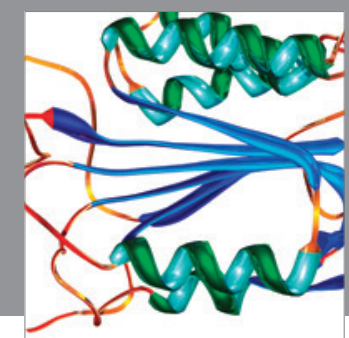

Disease Markers
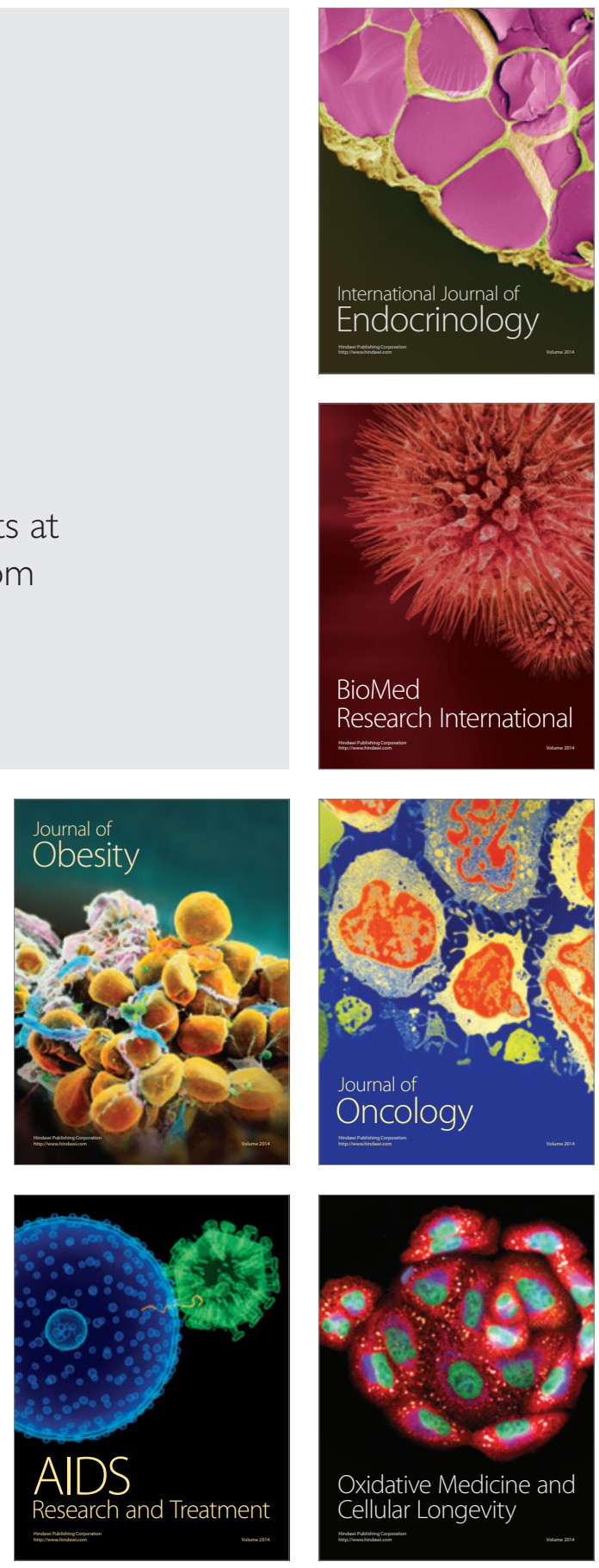